\title{
Economic, Cultural and Scientific Cooperation Between Divided Nations
}

\author{
Irwin Collier* and Yeon-Cheon $\mathrm{Oh}^{* *}$
}

\begin{abstract}
This article deals with the successful inter-German micro-relations and activities before reunification. The cooperation was achieved between the two German states through the functional approaches, such as travel and visit, transportation, inter-German trade, exchange of information and cultural cooperation and environment, etc. However, it is more desirable to conceive these as a result of concrete projects providing immediate payoffs which paved the way to workable procedures rather than an comprehensive effort which is designed to be an irresistible force of unification. From the German experience, Korea can learn following lesson: a little cooperation can not only go a long way to maintain the ties that bind but also cost a lot if Republic of Korea truly care for the welfare of currently famine-stricken people of the North.
\end{abstract}

Slightly more than a dozen years lie between today and the historical act of German reunification. The old and new federal states of Germany have been so busy fizing the damage of division that the details of the microrelations of intergerman relations before reunification are easily forgotten. But they were indeed the stuff of a concerted effort to improve people's lives in a time when the lasting division of Germany seemed the shared reality of Germans East and West. Then, as in Korea today, the odds were great against any single act of cooperation leading to much beyond a temporary solution to an isolated problem. However, like the proverbial dog that could talk: one is hardly surprised that the dog spoke so poorly, but it was still a miracle that the dog could talk at all.

Let us recall together some of the relatively mundane efforts to facilitate travel und visits between the two German states, to improve transportation links by building highways and bridges, to expand intergerman trade, to promote the exchange of information and cultural cooperation, and to protect the environment. These should not be misunderstood as efforts that cumulatively provided an irresistible force that ultimately resulted in German reunification but rather as concrete projects offering immediate payoffs that helped to establish workable procedures for potential projects in the future.

One of the important lessons learned over the decades of German division was that a mere denial of the legitimacy of that division was counterproductive in overcoming some of its worst consequences. The Federal Republic eventually accepted the reality of the GDR being another German state, while at the same time the GDR had the insight into the necessity of living with the uncomfortable reality that the Federal Republic could not be forced to renounce its belief in the unity of the German nation. Both sides

\footnotetext{
* Professor: Free Berlin University, Germany

** Dean, Graduate school of Public Administration, Seoul National University, Korea
} 
in intergerman negotiations were more or less aware of the goals and the acceptable tradeoffs of those sitting across the table on any issue: West Germany could be counted upon to provide economic or financial concessions with the undesirable effect of directly working to stabilize the GDR regime in exchange for improvements in the conditions for travel and visits between the two Germanys. Greater travel and visits could positively be regarded as maintaining the historical national identity that linked Germans East and West to one another and negatively (from the official GDR point of view) as slowing the growth of a separate socialist national identity. No less important for the management of the division of Germany was the vulnerability of West Berlin. The Federal Republic was willing to pay to maintain the transportation and communication links between West Berlin and the Federal Republic, and the city of West Berlin was compelled to find practical solutions to problems of waste disposal, water supply, as well as to meet the needs of West Berliners to maintain the personal and family ties broken by the Berlin Wall. In any event, not being in a position to challenge the U.S., British, French and Soviet claims for being in Berlin, the GDR still had the opportunity of extracting a toll. This includes DM payments for East German road and highway construction with the added benefit of being the sole bidder for contracts as well as generous lump-sum DM payments for use of the transit routes. The GER learned to act like any self-respecting monopolist, i.e. revenue maximization and not supply minimization became its goal in negotiations.

Over the final few years of the GDR the export of citizens who had one way or other forced the recognition of their desire to emigrate to the Federal Republic resulted in a payment of $100,000 \mathrm{DM}$ to the GDR per emigre. When one considers that approximately one million East Germans had been estimated at the time by the West German representation as actually wanting to emigrate, this could have easily become a third source of steady DM income for the GDR, had the Berlin Wall not fallen in 1989.

Intergerman trade was a link that proved particularly robust to changes in the political climate. With the exception of the Berlin blockade, there was really no time during which trade was not conducted between the two Germanys. The framework for intergerman trade created in 1951 was still in force at the time of unification (Sept. 20, 1951 Berlin Agreement). Like a successful constitution, the agreement was amended over the course of its life. According to the terms of that agreement intergerman trade would not be considered foreign trade. Intergerman trade offered the GDR three important economic advantages: (i) through the clearing mechanism dedicated to intergerman trade, East Germany was able to purchase western goods without actually making payment in a convertible currency; (ii) an interest free overdraft (amounting to 850 Million VE=DM over the period 1986-90), and (iii) access to EU market without customs duties.

In the 1980s among the trading partners of East Germany, the Federal Republic actually ranked second accounting for about a tenth of the total volume of the GDR's foreign trade, (in first place of course was the USSR with around two fifths of GDR foreign trade). Intergerman trade was about $40 \%$ of all the GDR's trade with Western countries according to OECD statistics. But such statistics reveal far more about the relative economic importance for the GDR than it does for the Federal Republic for 
which intergerman trade only accounted for about $2 \%$ of its total trade with all trading partners.

Examples of larger projects include that for the cross-border mining of potash (1984) and as well as an agreement with Volkswagen AG (1984) for the license production in the GDR of $300,000 \mathrm{VW}$ engines annually. Eventually by 1990 the agreement foresaw the annual GDR delivery of 100,000 engines to Volkswagen.

As mentioned earlier the modalities of finance for intergerman trade could be and were indeed linked to noneconomic concessions.

Two Examples. In 1984 travel by West Germans to the GDR was facilitated in response to a 950 million DM credit guaranteed by the Federal Republic. The continuation of the Swing credit as well as its increase agreed to in 1985 was linked to the GDR clearing its mine fields that ran along the border between East and West Germany.

Also worth mentioning are numerous contacts of a technical nature that functioned well even in the absence of formal contracts and agreements signed by the two Germanys such as the framework governing postal service between the two German states. Until 1968, compensation payments were settled via the Allied Working Party that had been established by the Allied Control Council in 1947. This was followed by direct lump sum payments made by the Federal government. By the second half of the 1990s the annual western lump sum payment was 200 million DM.

Direct telephone connections between East and West Berlin had been broken off by the GDR in 1952 with negotiations to reinstate telephone service started in September 1969. Between 1970 and 1980 the number of west to east telephone calls increased by a factor of 33 (i.e. an average increase of $35 \% /$ year)

Negotiations of the following years resulted in major improvements of the cooperation. Two agreements were signed in 1985, involving the construction of fibre-optic connection and digital connection between West Germany and West Berlin that were to provide a capacity for about 60,000 and 2,000 telephone calls, respectively.

Another good example of intergerman relations that had existed before explicit government agreements came into play involves the railroads. Beginning 1949, cross-border train service was within the framework of the Helmstedt agreement between the respective railroad administrations. Annually rail schedules were discussed and coordinated. Up until 1965 even the same passenger ticket prices were charged.

Before we move to the issue of cultural relations between the Germanys, it is necessary to discuss briefly the watershed agreement, the East-West Basic Treaty of 1972, that constituted the critical mass of sufficient compromises that helped pave the way for many other agreements. The East-West Basic Treaty was the first state treaty between East and West Germany. From this treaty followed about thirty related agreements, protocols, explanations to the protocols, agreements, and official correspondence re- 
garding the contract. These included an agreement governing transit to West Berlin, another governing travel and visits between East and West Berlin.

Contemporaneous to negotiations of the East-West Basic Treaty was the Transportation Treaty between the two Germanys which included protocols regarding inland navigation and cross-border railroad traffic, an agreement concerning West Berlin waste disposal into the GDR, a protocol for the emergency medical care of visitors to the GDR and an agreement about settlement of damages related to traffic accidents. As one can see, a considerable backlog of practical issues became resolvable once an adequate framework had been put into place.

The Federal Republic consistently and vigorously maintained that this treaty could not be construed as its blessing for the continued existence of two German states, but was only intended as providing a Modus-Vivendi. The Treaty was unsatisfactory in many respects being little more than the expression of the least common denominator: both contractual parties expressed a willingness to seek agreement on practical and humanitarian questions in the framework of normalization of their relations.

With all its shortcomings and ambiguities that would provide the seed for future disagreements about obligations and interpretations, the East-West Treaty nonetheless brought about many improvements for the East German population. It opened up more possibilities for travel to West Germany, e.g. for family reunification, with spouses allowed to join their partners in the west and parents moving to live near their children. Furthermore, West Germans living within defined areas close to the intergerman border were given much easier access to the East. This resulted in the rebuilding of relations to family and neighbours divided by a border but still neighbours in a geographic sense. Approximately six million West Germans were eligible for "small border visits" as they were called. Four new border crossings were opened up. One of the touchstones for the Federal Republic's evaluation of the effectiveness of its intergerman policies was whether visible improvements in the lives of individual Germans could be seen from the any particular agreement.

In one of the appendices to the East-West Basic Treaty both Germanys pledged to develop cultural cooperation and to begin negotiations for an agreement. While at one time in German history the mention of the word "culture" could lead men to reach for their revolvers, under communist rule the word "culture" meant reaching for the nearest agit-prop carde (agitation and propaganda). It comes perhaps as little surprise that in this realm, agreements were particularly hard to achieve.

Indeed in 1975 the cultural negotiations were broken off by the GDR side following the GDR demand that all items of cultural heritage moved during World War II to West Germany be returned to East Germany. Without a cultural framework for cooperation, few photo exhibitions and film festivals had any chance to be seen in the other part of Germany.

The second half of the 1970s was an explosive time for GDR cultural policy following the public protest of many East German writers, artists and performers against the expatriation of the well-known poet/folk-singer Wolf Biermann. This too put a deep chill on East-West cultural cooperation. 
After the meeting of Schmidt-Honecker in December 1981, the climate began to improve for cultural cooperation. In 1982 several important exhibitions traveled to the other Germany. In September 1983, a second phase of cultural negotiations was started however, the outstanding question still in dispute (i.e. the return of major items of cultural heritage to their pre-war locations) was deliberately not addressed. Finally, in May 1986 (after 14 years of negotiation) the Agreement on Cultural Cooperation was signed.

This agreement explicitly named the institutions and organizations which were allowed to participate in the cultural exchange, including commercial cultural exchange in the fields of music and publishing. Education and science were included in the cultural agreement as well. The broad spectrum of permitted activities included exhibitions, theatre performances, festivals, the exchange of information, and literature. Soon after the agreement went into effect, the hard problem of arranging the mutual return of archival and objects from museum collections was tackled. More artists from the East were granted permission to work for a limited period in the West, and the East German public were given the opportunity to see Western theatre productions at home.

The last substantive area of intergerman cooperation that we have time to address is environmental protection. The legal basis for cooperation was a protocol added to the East-West Basic Treaty that addressed the need for both Germanys to avert environmental damages and dangers for the other side. These negotiations too were broken off for political reasons in the 1970s and negotiations were only able to resume in the early 1980s. One of the main problems successfully solved involved the water treatment (desalination) of the Werra river. The GDR demanded the transfer of West German technology and objected to the polluter-pays-principle. In the end an agreement was reached with the Federal Republic paying 18 mill. DM. An enormous complicating factor was that GDR data on water and air pollution were treated as government secrets. This is clearly the kind of stumbling block that gave the international aid agencies so much trouble in providing food assistance to North Korea during its recent famine.

Both Germanys were signatories to various varied international treaties on environmental protection and both participated in UNO environmental programs. After the restart of negotiations in 1985 a new agreement on environmental protection could be signed on the occasion of Honecker's visit to the Federal Republic. The agreement covered air pollution, damages to forests, waste disposal, protection of the natural environment and water. To implement the agreement, meetings of experts, exchange of scientists and improvements of information exchange were agreed upon as well.

Environmental protection emerged as a topic of growing importance in both German states at the end of the 1970s. The East German leadership opposed the environmental movement with grass-roots growing outside of its state controlled mass organizations. The East German communist party was alarmed about the many private meetings between Eastern and Western groups discussing environment initiatives, especially in Berlin during the years 1988 and 1989. These groups constituted an important medium for the protest movement of the GDR opposition against the political, economic and ecological reality of the GDR in the 1980s.

Looking back we can see that when cooperation was achieved between the two German states was successful, it could actually contribute to making life in the divided 
nation more bearable for many people, East and West. There were setbacks and disappointments and more than one instance of attempts to sell the same horse twice to the Federal Republic (or selling and taking back the horse)

Illustration. On November 11, 1973 the GDR doubled the amount of the minimum exchange Western visitors were required to convert with no refund for unspent balances. As the law of demand would predict, this increase in the cost of a visit to the GDR resulted in an abrupt decline of the number of visitors to the East. During the renegotiation of the terms of the swing credit, the Federal Republic was able to get this increase reduced. However, again in November 1980 the minimum exchange required for Western visitors was raised with the number of visitors to the GDR falling by $24 \%$ and from West Berlin to East Berlin by $60 \%$ compared to the numbers a year earlier. In the years that followed, the number of visitors remained much lower than before the increase. Later a reduction in the minimum exchange demanded of pensioners went into effect following loan guarantees to the GDR for roughly a billion DM in 1983.

We have only been able to highlight a few of the cases of intergerman cooperation in divided Germany for this presentation. If there are lessons in the German experience for policymakers in Korea, the first is that a little cooperation can go a long way to maintain the national and family ties that bind and the second is that if you genuinely care for the welfare of those living under a state that is more concerned with its own self-preservation, a little cooperation cal cost you a lot.

Unfortunately in matters of policy it is seldom the case that one suit fits all. At the very least interkorean cooperation requires far more attention to matters of military security than did the nation divided between two alliances. Still the experience of nations divided is extremely limited and it is perfectly legitimate to draw inspiration from the experience of others. That, plus it is always a valid question to ask, what was behind any other nation's success?

\section{Bibliography}

Bundesministerium fur innerdeutsche Beziehengen. 1979. Zehn Zahre Deutschlandpolitik/Die Entwicklung der Beziehungen zwischen der Bundesrepublik Deutschland und der Deutshcen Demokratischen Republik 1969-1979.

Bundesministerium fur innerdeutsche Beziehungen. 1986. Innerdeutsche Beziehungen, Die Untwicklung der Beziehungen zwischen der Bundesrepublik Deutschland und der Deutschen Demokrationschen Republik 1980-1986.

Weidenfeld, Werner and Karl/Rudolf Korte (eds.). 1999. Handworterbuch zur deutschen Einheit. Campus Verlag. Frankfurt. 